Professor Norton A. Kent, of Boston University, then addressed the meeting on "Variability of Wave Lengths of the Spectrum Lines". After explaining the grating spectroscope in general, he deseribed the particular apparatus which he used in his investigations. Strips of photographic plates were exposed and a trifle expesure was made on each in such a way that an are spectrum occupied the center of the plate with the spark spectrum above and below it. Apparatus use l for producing the spark "was shown, also numerous lantern slides make from the original plates were suown.

The Symposium on Useful Laboratory Manipulations followed the address of Professor Kent. Messrs. Boylston, Greenlaw, Hyde, Tilley, Rice and Palmor presenting new methods. Professor Hall described an apparatus to show the friction of air in tubes; he also demonstrated a new method for measuring surface tension.

At tho close of the program a vote of thanks was extended to Professor Kent for his address, and to Boston University for the use of the laboratories.

C. H. $\mathrm{S}$.

\title{
MATHEMATICAI CONFERENCE.
}

H. E. SLAUGHT.

University of Chioago.

The Anpual Conference in Mathematies at the University of Chicago, November 16, 1908, was attended by about forty teachers and much interest was developed in the discussion of the improvement of the teaching of Geometry. The discussion was opened by Principal H. W. Hurt, of Oskaloosa, Iowa, and carried on with vigor by numerous volunteers from various representative schools, including the University of Chicago High School, the Manual Training High School of Indianapolis, Indiana, and the Evanston High School. The chief lines of discussion are indicated by the following questions, which were proposed in connection with the call for the conference:

\section{IMPROVEMENT IN THE TEACHING OF GEOMETRY.}

1. Is Geometry as now taught sufficiently in touch with the world in which the pupil lives?

2. Is the pure logic of Geometry as currently given adapted to the average second-year high-school pupil?

3. Shoula the time-worn dictum "Geometry for mental discipline" be the sole criterion?

4. What suggestions from your own experience will you propose for improving the-Geometry situation?

Discussion opened with a brief address by Principal H. W. Hurt, Oskaloosa, Towa.

There seems to be a widespread feeling among the teachers of geometry throughout the Middle West that the schools are not doing their full duty in respect to this subject. It is very generally believed that too much formal logic and too many unrelated and abstract propositions are forced upon the beginning pupil and not enough opportunity is given for conerete illustrations and everyday uses of geometry. It is interesting to note that this same question eame up at the Thanksgiving meeting of the Central Association of Science and Mathematies Teachers, and that a committee of this association has been appointed to collect material for concrete applications of Geometry. 